\title{
Expression of B cell-specific Moloney murine leukemia virus integration site 1 in vulvar squamous cell carcinoma and its effect on the biological behavior of A-431 cells
}

\author{
XUELI BAI, LING OUYANG, BO LI, YANG ZHOU and XIN WEN \\ Department of Gynecology, Shengjing Hospital of China Medical University, Shenyang, Liaoning 110004, P.R. China
}

Received December 3, 2014; Accepted July 30, 2015

DOI: $10.3892 / \mathrm{ol} .2015 .3754$

\begin{abstract}
The aim of the present study was to investigate the expression of B cell-specific Moloney murine leukemia virus integration site 1 (BMI-1) in vulvar squamous cell carcinoma (VSCC) and vulvar intraepithelial neoplasia (VIN). Furthermore, the present study investigated the effects of BMI-1 expression on the biological behavior of A-431 human epidermoid carcinoma cells. BMI-1 expression in human VSCC and VIN tissues was detected using immunohistochemistry. Subsequently, BMI-1 expression was silenced in A-431 cells using small interfering RNA (siRNA), and BMI-1 expression was detected using reverse transcription-quantitative polymerase chain reaction and western blotting. The effects of BMI-1 silencing on cell proliferation, apoptosis and invasive ability were determined using an MTT assay, Annexin V-fluorescein isothiocyanate/propidium iodide double-labeling experiment and Transwell assay, respectively. The expression rate of BMI-1 in normal vulvar, VIN and VSCC tissues was 0.0, 25.0 and 68.0\% respectively, demonstrating an increasing trend in the severity of the disease. BMI-1 overexpression was found not to correlate with age, pathological stage, lymph node metastasis or degree of differentiation $(\mathrm{P}>0.05)$. BMI-1 siRNA transfection effectively inhibited BMI-1 messenger RNA and protein expression in A-431 cells. The mean rate of apoptosis promotion and proliferation inhibition in the most effectively silenced group were 20.19 and $46.82 \%$, respectively, which was significantly higher than that of the cells in the blank and control siRNA groups $(\mathrm{P}<0.05)$. The number of invading cells was decreased in the most effectively silenced group compared with that of the blank and control siRNA groups. Abnormal expression of BMI-1 was also detected in VIN and VSCC tissues, and targeting of BMI-1 with siRNA was able to successfully silence BMI-1 expression in A-431 cells. Silencing of BMI-1 promoted apoptosis and inhibited the invasive abilities of A-431 cells in vitro.
\end{abstract}

Correspondence to: Dr Ling Ouyang, Department of Gynecology, Shengjing Hospital of China Medical University, 36 San-Hao Street, Shenyang, Liaoning 110004, P.R. China

E-mail: baixueli123@126.com

Key words: vulvar neoplasms, vulvar intraepithelial neoplasia, B cell-specific Moloney murine leukemia virus integration site 1, small interfering RNA, proliferation, apoptosis, invasion

\section{Introduction}

Vulvar cancer is the fourth most common gynecological cancer worldwide, comprising $5 \%$ of total malignancies observed in the female reproductive tract (1). Squamous cell carcinoma is the most commonly observed pathological type of vulvar cancer (2). Vulvar carcinoma is most frequently diagnosed in postmenopausal females and the mean age at diagnosis has been revealed to be 65 years, although this number has been observed to be decreasing (3). In recent years, vulvar squamous cell carcinoma (VSCC) incidence has increased (4). Vulvar intraepithelial neoplasia (VIN) is the precursor lesion of VSCC and its incidence is also increasing, according to data from the Surveillance, Epidemiology, and End Results Program (4). Young patients with VIN generally heal spontaneously without treatment, howvever, patients $>60$ years old or young patients with immunosuppression may develop invasive cancer.

B cell-specific Moloney murine leukemia virus integration site 1 (BMI-1) is a stem cell factor and member of the polycomb group (PCG) family (5). BMI-1 is important for cell cycle progression, cell immortalization and senescence, and has been reported to regulate the proliferative activities of normal, stem and progenitor cells (6). Numerous studies have demonstrated that BMI-1 expression, which is upregulated in multiple types of cancer, is positively correlated with clinical grade/stage and poor prognosis in cervical (7), ovarian (8), endometrial (9) and lung (10) cancer. Silencing of BMI-1 expression by RNA interference (RNAi) has been observed to decrease the rate of tumor cell growth, resulting in cell cycle arrest and inhibition of the invasive ability of tumor cells (11-14). In the present study, BMI-1 expression in VSCC was examined, and the effect of small-interfering RNA (siRNA)-mediated silencing of BMI-1 in A-431 cells was investigated.

\section{Materials and methods}

Tissue samples. All experiments were approved by the Ethics Committee of China Medical University (Liaoning, China). A total of 125 paraffin-embedded tissue specimens, including 75 VSCC, 40 vulvar intraepithelial neoplasia (VIN) and 10 normal vulvar samples adjacent to the carcinoma, were subjected to immunohistochemical analysis. The samples used in the present study were obtained from the Department of Pathology of Shengjing Hospital (Liaoning, China). Tissue 

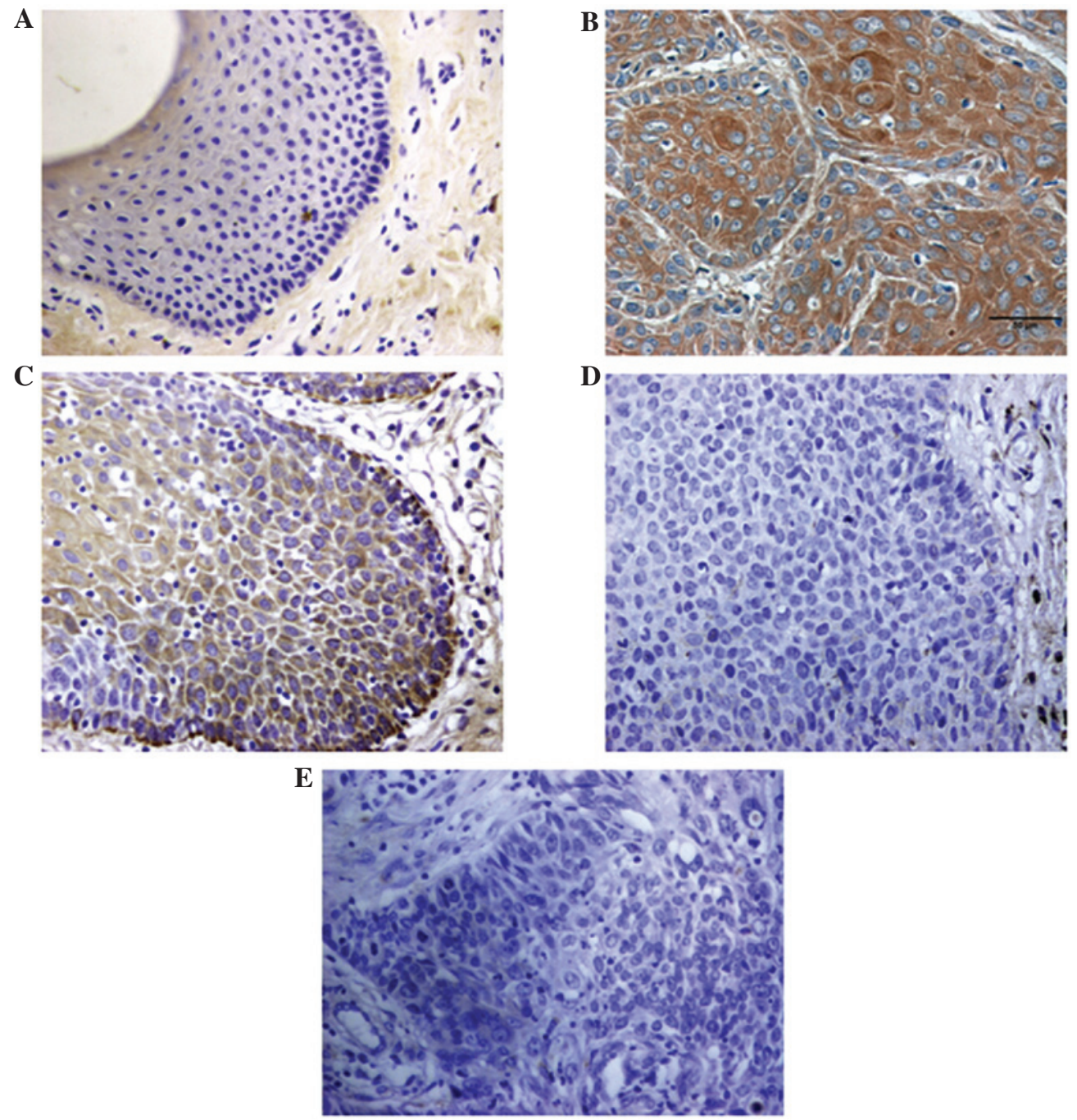

Figure 1. Immunohistochemical staining of B cell-specific Moloney murine leukemia virus integration site l protein in VSCC, VIN and adjacent normal vulvar tissues. (A) Normal vulvar tissue adjacent to carcinoma, (B) positively stained VSCC tissue, (C) positively stained VIN tissue, (D) negative VIN tissue and (E) negative VSCC tissue; magnification, x400. VSCC, vulvar squamous cell carcinoma; VIN, vulvar intraepithelial neoplasia.

samples were obtained during routine biopsies of the vulva or vulvectomies. Representative immunohistochemically stained sections of epithelium, including the adjacent mucosa, were examined using light microscopy (BX60; Olympus Corporation, Tokyo, Japan). VSCC samples were pathologically staged according to the International Federation of Gynecology and Obstetrics 2009, and divided into the following: 43 VSCC grade I, 16 VSCC grade II and 16 VSCC grade III tumors. The median age of patients with VSCC was 55 years (range, 39-74 years). The median age of patients with VIN was 43 years (range, 23-68 years). and the median age of individuals with normal vulvar tissue was 59 years (range, 38-68 years). No statistically significant differences were observed between the three age distribution groups $(\mathrm{P}>0.05)$.

Immunohistochemistry. Serial longitudinal sections ( $4 \mu \mathrm{m})$ were cut, placed onto slides, de-waxed in xylene (Sinopharm Chemical Reagent Co., Ltd., Shanghai, China) and rehydrated in graded ethanol (Sinopharm Chemical Reagent Co., Ltd.) and distilled water. Sections were treated with $\mathrm{H}_{2} \mathrm{O}_{2}$ (Sinopharm Chemical Reagent Co., Ltd.) prior to immunostaining in order to block endogenous peroxidase activity.
For immunohistochemical staining, sections were incubated with primary antibody (rabbit monoclonal anti-human BMI-1; cat no. sc-10745; 1:400 dilution; Santa Cruz Biotechnology, Inc., Dallas, TX, USA) in a refrigerator at $4^{\circ} \mathrm{C}$ overnight, at room temperature for $40 \mathrm{~min}$, then in a $37^{\circ} \mathrm{C}$ incubator for $40 \mathrm{~min}$. Subsequently, the sections were incubated with horseradish peroxidase (HRP)-labeled streptavidin-biotin kit system (BIOSS, Beijing, China) in a $37^{\circ} \mathrm{C}$ incubator for $30 \mathrm{~min}$. Binding of antibodies was visualized using 3,3'-diaminobenzidine (Sinopharm Chemical Reagent Co., Ltd.), developed under light microscopic control to optimize contrast. Sections were then counterstained with hematoxylin (Beyotime Institute of Biotechnology, Shanghai, China), dehydrated through graded ethanol and xylene and embedded. Immunohistological evaluation of the paraffin-embedded sections was performed by scoring two aspects as follows: Staining intensity [no (0), weak (1), medium (2) and strong (3)] and the percentage of positive tumor cells $[<5 \%(0), 5-25 \%(1)$, $26-50 \%$ (2), $51-75 \%$ (3) and $>75 \%$ (4)]; the total score was the sum of the two individual scores. BMI-1 expression was scored as follows: 0 and 1,(-); 2 and 3,(+); 4 and 5,(++); 6 and 7,(+++). BMI-1 overexpression was indicated by $(++)$ and $(+++)$. 
Table I. Expression of BMI-1 in various types of vulvar tissue.

\begin{tabular}{|c|c|c|c|c|}
\hline \multirow[b]{2}{*}{ Tissue organization } & \multirow[b]{2}{*}{ Cases, $\mathrm{n}$} & \multicolumn{2}{|c|}{ Expression of BMI-1, n (\%) } & \multirow[b]{2}{*}{ P-value } \\
\hline & & Positive & Negative & \\
\hline Normal & 10 & $0(0)$ & $10(100)$ & $<0.0001^{\mathrm{a}}$ \\
\hline Vulvar intraepithelial neoplasia & 40 & $10(25)$ & $30(75)$ & $<0.0001^{\mathrm{b}}$ \\
\hline Vulvar squamous cell carcinoma & 75 & $51(68)$ & $24(32)$ & $<0.0001^{\mathrm{c}}$ \\
\hline
\end{tabular}

BMI-1, B cell-specific Moloney murine leukemia virus integration site $1 .{ }^{\mathrm{a}} \mathrm{vs}$. vulvar intraepithelial neoplasia tissue; ${ }^{\mathrm{b}} \mathrm{vs}$. vulvar squamous cell carcinoma; ${ }^{\mathrm{c}} \mathrm{vs}$. normal tissue.

Table II. Correlations between BMI-1 expression and clinicopathological parameters.

\begin{tabular}{|c|c|c|c|c|}
\hline \multirow[b]{2}{*}{ Clinicopathological parameter } & \multirow[b]{2}{*}{ Cases, $\mathrm{n}$} & \multicolumn{2}{|c|}{ BMI-1, n (\%) } & \multirow[b]{2}{*}{ P-value } \\
\hline & & $++/+++$ & $-/+$ & \\
\hline Age, years & & & & 0.921 \\
\hline$<60$ & 40 & $27(67.5)$ & $13(32.5)$ & \\
\hline$\geq 60$ & 35 & $24(68.6)$ & $11(31.4)$ & \\
\hline Lymphatic metastasis & & & & 0.336 \\
\hline Positive & 15 & $8(53.3)$ & $7(46.7)$ & \\
\hline Negative & 60 & $40(66.7)$ & $20(33.5)$ & \\
\hline Differentiation degree & & & & 1.000 \\
\hline Moderate & 25 & $18(72.0)$ & $7(28.0)$ & \\
\hline High & 50 & $36(72.0)$ & $14(28.0)$ & \\
\hline Clinical stage & & & & 0.632 \\
\hline I-II & 59 & $10(23.3)$ & $33(76.7)$ & \\
\hline III & 16 & $9(28.2)$ & $23(71.9)$ & \\
\hline
\end{tabular}

BMI-1, B cell-specific Moloney murine leukemia virus integration site 1.

Cell line. The A-431 human epidermal squamous cell line was obtained from the China Medical University Center laboratory (Liaoning, China) and grown in Dulbecco's modified Eagle's medium (Gibco Life Technologies, Carlsbad, CA, USA) supplemented with $10 \%$ fetal bovine serum (Beyotime Institute of Biotechnology). The cells were maintained at $37^{\circ} \mathrm{C}$ in a humidified atmosphere of $5 \% \mathrm{CO}_{2}$.

BMI-1 silencing by siRNA. Three siRNA constructs, which were obtained from Shanghai GenePharma Co., Ltd. (Shanghai, China), were designed and synthesized according to the GeneBank NM-005180 gene sequence (http://www.ncbi.nlm. nih.gov/genbank), and one control siRNA was obtained from Shanghai GenePharma Co., Ltd. All siRNA constructs were labeled by segment fluorescein by Shanghai GenePharma Co., Ltd. The sequences were as follows: BMI-1 siRNA-1 sense, 5'-CCAGACCACUACUGAAUAUTT-3' and antisense, 5'-AUAUUCAGUAGUGGUCUGGTT-3'; BMI-1 siRNA-2 sense, 5'-GGAUCGGAAAGUAAACAAATT-3' and antisense, 5'-UUUGUUUACUUUCCGAUCCTT-3'; BMI-1 siRNA-3 sense, 5'-CCAGAUUGAUGUCAUGUAUTT-3' and antisense, 5'-AUACAUGACAUCAAUCUGGTT-3'; negative control sense, 5'-UUCUCCGAACGUGUCACGUTT-3' and antisense, 5'-ACGUGACACGUUCGGAGAATT-3'. A-431 cells were transfected using Lipofectamine ${ }^{\circledR} 2000$ Reagent (Invitrogen Life Technologies, Carlsbad, CA, USA) at $70 \%$ confluency. The optimal time of transfection was $24 \mathrm{~h}$ (transfection efficiency $\geq 80 \%$ ), as determined by fluorescence microscopy (BX51TF; Olympus Corporation). Western blotting and reverse transcription-quantitative polymerase chain reaction (RT-qPCR) were used to identify the most effective siRNA construct.

$R T$-qPCR assay. Following $24 \mathrm{~h}$ of transfection, total RNA was extracted from A-431 cells using TRIzol reagent (Invitrogen Life Technologies) The primers used were as follows: BMI-1 sense, 5'-TGGACTGACAAATGCTGGAGA-3' and antisense, 5'-GAAGATTGGTGGTTACCGCTG-3'; $\beta$-actin sense, 5'-CATTAAGGAGAAGCTGTGCT-3' and antisense, 5'-GTTGAAGGTAGTTTCGTGGA-3' (Shanghai GenePharma Co., Ltd.). RT-qPCR reactions were performed using the SYBR Green method with the AccuPower Greenstar qPCR Master mix (Bioneer Corp., Daejeon, Korea) on a Rotor-Gene 6000 (Corbett Research Pty Ltd., Sydney, Australia). 
Table III. Relative expression levels of BMI-1 mRNA $24 \mathrm{~h}$ following transfection.

\begin{tabular}{lcc}
\hline Group & $\begin{array}{c}\text { Relative levels } \\
\text { of BMI-1 mRNA }\end{array}$ & P-value $^{\mathrm{a}}$ \\
\hline A-431 cell & $5.48 \pm 0.15$ & \\
Negative & $5.56 \pm 0.15$ & \\
siRNA-1 & $3.01 \pm 0.16$ & $<0.0001$ \\
siRNA-2 & $0.10 \pm 0.13$ & $<0.0001$ \\
siRNA-3 & $2.45 \pm 0.14$ & $<0.0001$ \\
\hline
\end{tabular}

${ }^{\mathrm{a}}$ Vs. A-431 cell group, t-test. Data are expressed as the mean \pm standard deviation. BMI-1, B cell-specific Moloney murine leukemia virus integration site 1; siRNA, small interfering RNA; mRNA, messenger RNA.

Table IV. Relative protein expression levels of BMI-1 and GAPDH $24 \mathrm{~h}$ following transfection.

\begin{tabular}{lrcr}
\hline Group & \multicolumn{1}{c}{ BMI-1 } & GAPDH & P-value $^{\mathrm{a}}$ \\
\hline A-431 cell & $68.71 \pm 3.05$ & $267.91 \pm 2.49$ & \\
Negative & $70.72 \pm 4.27$ & $267.66 \pm 4.35$ & \\
siRNA-1 & $40.92 \pm 4.31$ & $263.77 \pm 3.20$ & $<0.0001$ \\
siRNA-2 & $6.26 \pm 1.24$ & $268.36 \pm 5.35$ & $<0.0001$ \\
siRNA-3 & $29.76 \pm 2.08$ & $264.88 \pm 3.04$ & $<0.0001$
\end{tabular}

${ }^{\mathrm{a}}$ vs. A-431 cell group, t-test. Data are expressed as the mean \pm standard deviation. BMI-1, B cell-specific Moloney murine leukemia virus integration site 1; siRNA, small interfering RNA.

Table V. Survival rates of A-431 cells $24 \mathrm{~h}$ following siRNA transfection.

\begin{tabular}{lc}
\hline Group & Survival rates, \% \\
\hline A-431 & $98.77 \pm 0.98$ \\
Negative control & $98.79 \pm 1.74$ \\
siRNA transfected & $53.17 \pm 1.53^{\mathrm{a}}$
\end{tabular}

${ }^{\mathrm{a}} \mathrm{P}=0.00$ vs. A-431 cell group, t-test. Data are expressed as the mean \pm standard deviation. siRNA, small interfering RNA.

The PCR reactions were conducted as follows: $94^{\circ} \mathrm{C}$ for $5 \mathrm{~min}$, amplification for 40 cycles with denaturation at $94^{\circ} \mathrm{C}$ for $20 \mathrm{sec}$, annealing at $61^{\circ} \mathrm{C}$ for $20 \mathrm{sec}$ and extension at $72^{\circ} \mathrm{C}$ for $20 \mathrm{sec}$. All experiments were performed in duplicate or triplicate. Relative expression was calculated using Relative Expression Software Tool 2009 software (Corbett Research Pty Ltd.).

Western blot assay. Total BMI-1 protein was isolated and quantified as follows: Cells transfected for $24 \mathrm{~h}$ were harvested, washed with ice-cold phosphate-buffered saline and lysed in lysis buffer (Beyotime Institute of Biotechnology) at $4^{\circ} \mathrm{C}$ for
Table VI. Apoptotic rates of A-431 cells $24 \mathrm{~h}$ following siRNA transfection.

\begin{tabular}{lc}
\hline Group & Apoptotic rates, \% \\
\hline A-431 & $5.75 \pm 0.08$ \\
Negative control & $5.63 \pm 0.11$ \\
siRNA transfected $^{\mathrm{a}}$ & $20.19 \pm 0.04$ \\
\hline
\end{tabular}

${ }^{\mathrm{a}} \mathrm{P}=0.00$ vs. A-431 cell group, t-test. Data are expressed as the mean \pm standard deviation. siRNA, small interfering RNA.

Table VII. Invasive potential of A-431 cells $24 \mathrm{~h}$ following siRNA transfection.

\begin{tabular}{lc}
\hline Group & Number of penetrating cells \\
\hline A-431 & $33.17 \pm 2.92$ \\
Negative control & $33.50 \pm 3.02$ \\
siRNA transfected $^{\mathrm{a}}$ & $21.67 \pm 2.42$ \\
\hline
\end{tabular}

${ }^{a} \mathrm{P}=0.00$ vs. A-431 cell group, t-test. Data are expressed as the mean \pm standard deviation. siRNA, small interfering RNA.
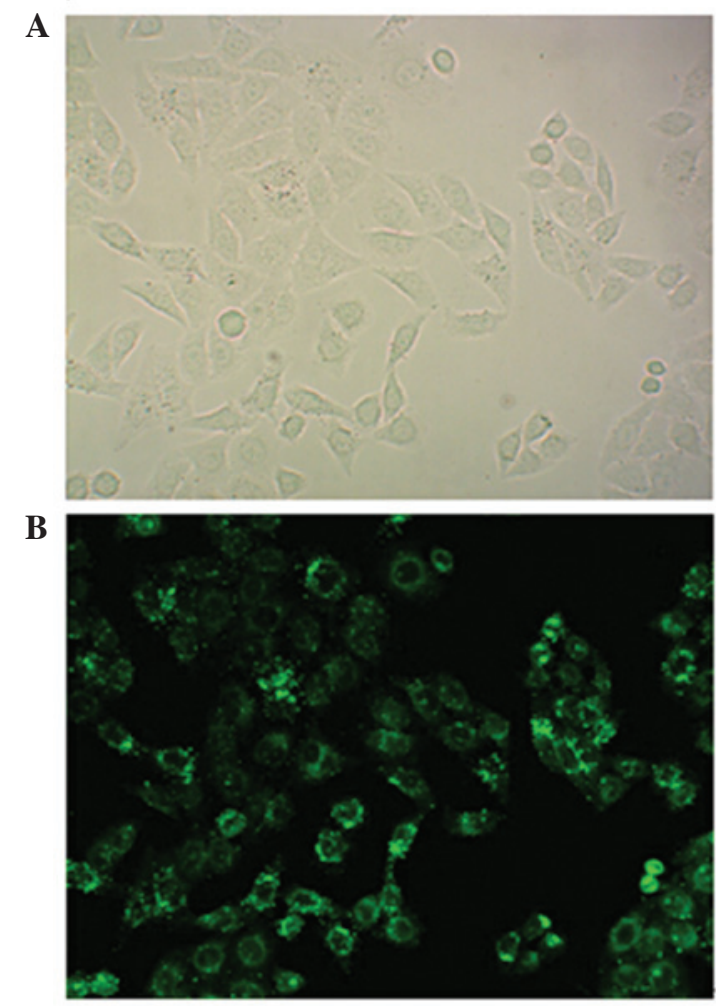

Figure 2 Evaluation of transfection efficiency of A-431 cells $24 \mathrm{~h}$ following transfection with small interfering RNA. (A) White light and (B) fluorescent light; magnification, $\mathrm{x} 400$.

$30 \mathrm{~min}$, followed by brief sonication (Vibra-Cell VCX750; Sonics \& Materials, Inc., Newtown, CT, USA). All experimental steps were performed on ice. Following centrifugation 


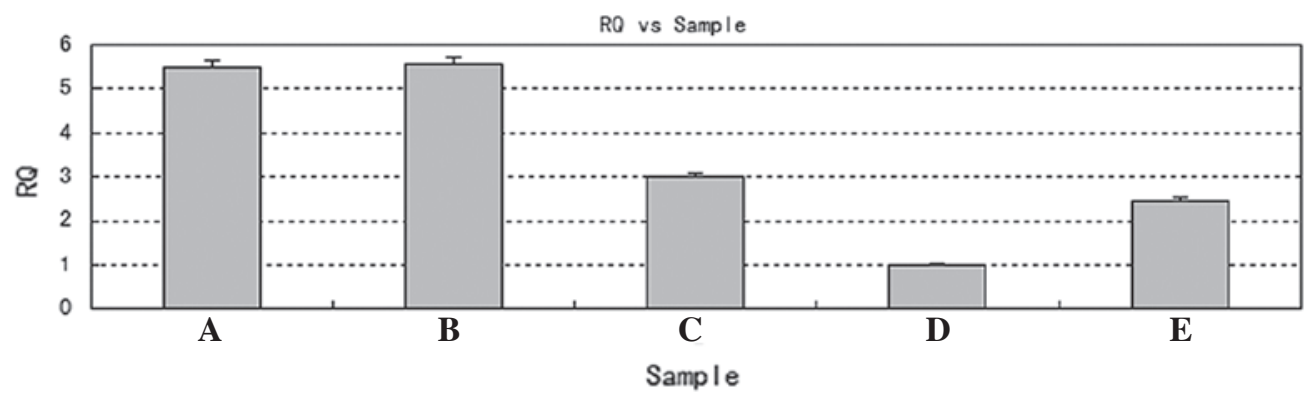

Figure 3. Reverse transcription-quantitative polymerase chain reaction assay of B cell-specific Moloney murine leukemia virus integration site 1 expression in A-431 cells $24 \mathrm{~h}$ following transfection: (A) Blank group, (B) negative control group, (C) siRNA-1 group, (D) siRNA-2 group and (E) siRNA-3 group. siRNA, small interfering RNA, RQ; relative quantification.

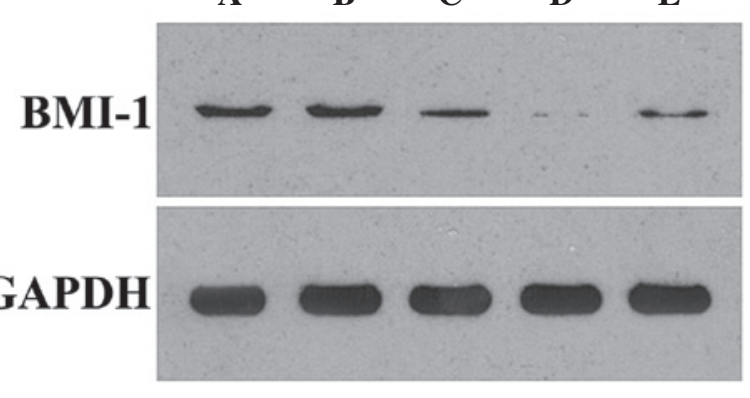

Figure 4. Western blot analysis of BMI-1 expression levels in A-431 cells $24 \mathrm{~h}$ following transfection. (A) Blank group, (B) negative control group, (C) siRNA-1 group, (D) siRNA-2 group and (E) siRNA-3 group. GAPDH was used as a protein loading control. siRNA, small interfering RNA; BMI-1, B cell-specific Moloney murine leukemia virus integration site 1.

at $16,000 \mathrm{xg}$ for $10 \mathrm{~min}$ at $4^{\circ} \mathrm{C}$, supernatants were collected and the protein concentration was measured using bicinchoninic acid assay reagent (BioTeke Corp., Beijing, China). Proteins were separated by $10 \%$ SDS-PAGE and transferred onto a polyvinylidene difluoride membrane (Immobilon-Ny+; both from Beyotime Institute of Biotechnology). Following saturation, the membranes were incubated at room temperature for $2 \mathrm{~h}$ in Tris-buffered saline with $0.1 \%$ Tween-20 (Beyotime Institute of Biotechnology) containing 5\% non-fat dry milk (Inner Mongolia Yili Industrial Group Co., Ltd., Hohhot, China). The membranes were subsequently incubated with primary antibodies against BMI-1 (1:400 dilution) overnight at $4^{\circ} \mathrm{C}$ and subjected to secondary detection using HRP-conjugated immunoglobulin $\mathrm{G}(\mathrm{H}+\mathrm{L})$ antibodies [goat anti-rabbit polyclonal; cat no. LK-GAR007; 1:4,000 dilution; Multi Sciences (Lianke) Biotech Co., Ltd., Hangzhou, China] at room temperature for $2 \mathrm{~h}$. Protein detection was performed using an LumiPico ${ }^{\circledR}$ enhanced chemiluminescence kit (Nanjing Keygen Biotech. Co. Ltd., Nanjing, China). GAPDH antibody (mouse anti-human monocloanl; cat no. sc-365062; 1:800 dilution; Santa Cruz Biotechnology, Inc.) was used as a protein loading control.

MTT assay. In order to measure cell growth, cells transfected for $24 \mathrm{~h}$ were seeded into 96 -well plates at a density of $1 \times 10^{5} / \mathrm{ml}$ in a volume of $100 \mu \mathrm{l}$, and allowed to grow for 6-8 h. Cells were then divided into three groups as follows: A blank group, transfected with an identical volume of opti-MEM medium/Lipofectamine 2000; a negative control group, transfected with negative control siRNA/Lipofectamine 2000; and a best transfection group, transfected with the most effective siRNA/Lipofectamine 2000. Twenty-four hours following transfection, $20 \mu \mathrm{l}$ MTT solution $(5 \mathrm{mg} / \mathrm{ml}$ in PBS; Beyotime Institute of Biotechnology) was added to each microtiter well and incubated for $4 \mathrm{~h}$ at $37^{\circ} \mathrm{C}$. Following aspiration of the medium, $200 \mu \mathrm{l}$ dimethyl sulfoxide (Beyotime Institute of Biotechnology) was added and mixed, and absorbance was measured at a wavelength of $570 \mathrm{~nm}$ (DU-730; Beckman Coulter, Inc., Brea, CA, USA). Cell survival rate was calculated as follows: [A-431(siRNA)/A-431(blank)] 100\%, where A-431(siRNA) is the absorbance of the cells transfected with siRNA and A-431(blank) is the absorbance of the cells not transfected with siRNA.

Apoptosis assay. Apoptosis was assayed using the Annexin V-fluorescein isothiocyanate (FITC) apoptosis kit (Beyotime Institute of Biotechnology). Briefly, cells transfected for $24 \mathrm{~h}$ were harvested and washed twice with PBS, followed by resuspension in $10 \mu \mathrm{l}$ Annexin V binding buffer. Subsequently, FITC-conjugated Annexin V and propidium iodide were added. Following incubation for $15 \mathrm{~min}$ at room temperature in the dark, an additional binding buffer was added and cells were incubated for $5 \mathrm{~min}$ at $6-8^{\circ} \mathrm{C}$. Samples were analyzed immediately by flow cytometry (Cell Lab Quanta $^{\mathrm{TM}}$ SC; Beckman Coulter, Inc.). Cells were divided into three groups as follows: Normal A-431 cells (without transfection), negative control group (transfected with negative control siRNA) and best transfection group (transfected with the most effective siRNA).

Transwell chamber invasion assay. The polycarbonate membranes (8 $\mu \mathrm{m}$-pores) of Transwell inserts were coated with Matrigel (BD Biosciences, San Jose, CA, USA). Cells were resuspended in serum-free minimum essential medium (MEM; Gibco Life Technologies) and seeded into the upper wells in the three groups described previously. MEM medium supplemented with $15 \%$ fetal bovine serum was placed into the lower chamber. Following incubation for $24 \mathrm{~h}$ at $37^{\circ} \mathrm{C}$, the inserts were removed and cells which had migrated through the membranes and attached to the lower chamber were photographed using an Olympus BX60 microscope and counted.

Statistical analysis. All experiments were performed a minimum of three times and the results were analyzed using 
A

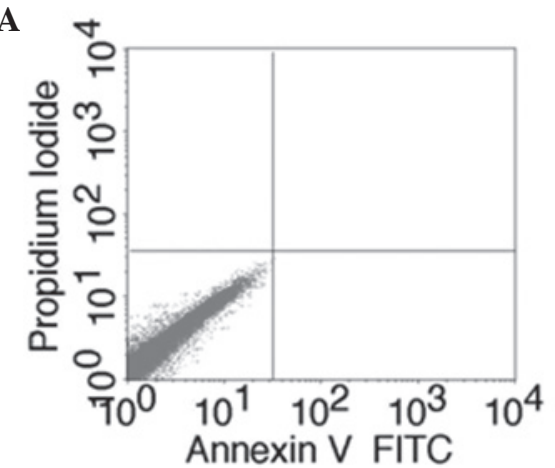

C

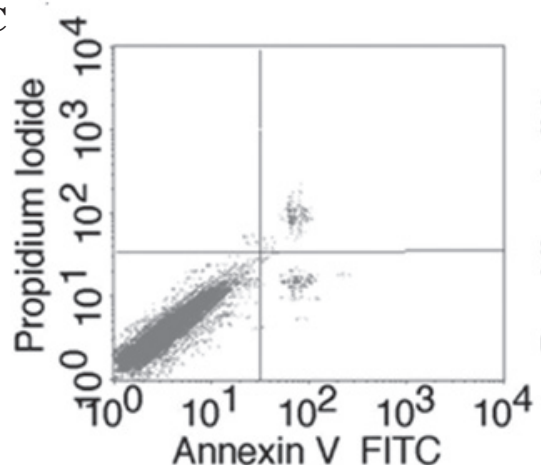

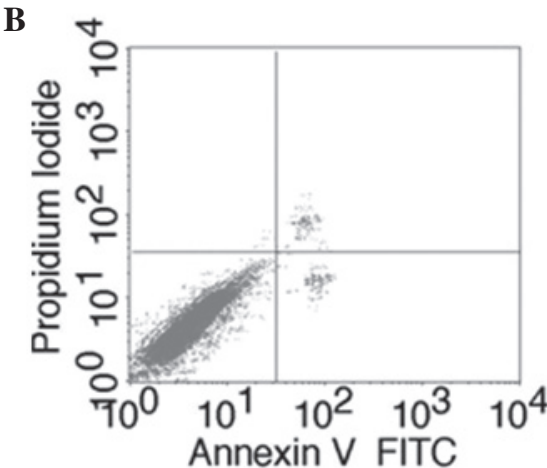

D

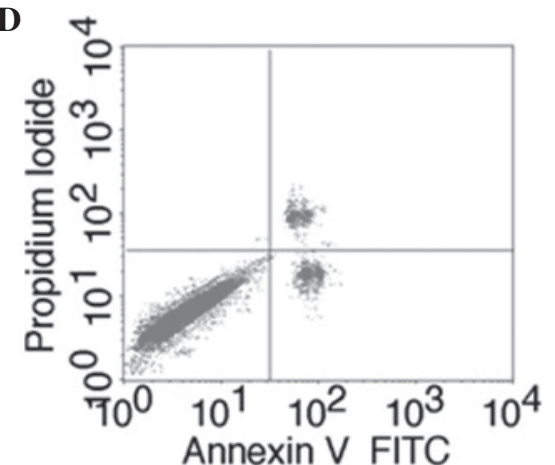

Figure 5. Apoptotic potential of A-431 cells $24 \mathrm{~h}$ following transfection. (A) System testing negative control figure, (B) blank A-431 cell group, (C) negative control group and (D) best transfected group. FITC, fluorescein isothiocyanate.
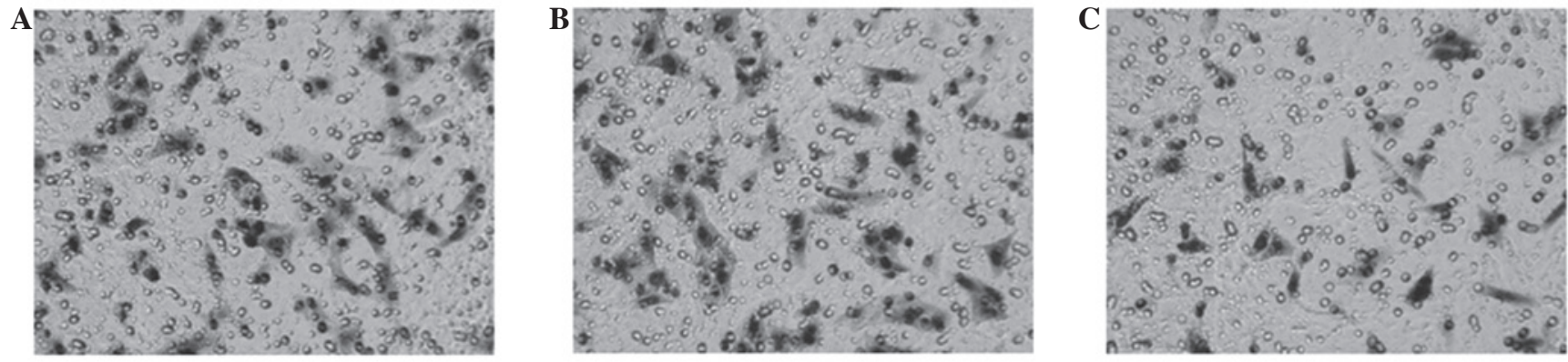

Figure 6. Invasive chamber invasion assay of A-431 cells $24 \mathrm{~h}$ after transfection with small interfering RNA. (A) Blank A-431 cell group, (B) negative control group and (C) best transfected group. Magnification, $\mathrm{x} 400$.

SPSS version 17.0 (SPSS Inc., Chicago, IL, USA). Values were expressed as the mean \pm standard deviation. The analysis of variance test was used when $>2$ groups were compared and $\mathrm{P}<0.05$ was considered to indicate a statistically significant difference.

\section{Results}

Differential expression of BMI-1 in VSCC, VIN and normal vulvar tissues. Immunohistochemical staining demonstrated that the expression rate of BMI-1 in VIN tissues differed significantly from that in normal vulvar tissues (25 vs. $0 \%$; $\mathrm{P}<0.05)$. In addition, the positive expression rate of BMI-1 in VSCC tissues significantly differed from that in VIN and normal vulvar tissues $(68.0$ vs. $25.0 \%$ and $0 \%$; both $\mathrm{P}<0.0001$; Fig. 1; Table I). BMI-1 protein overexpression was not observed to be correlated with age, pathological stage, lymph node metastasis or degree of differentiation $(\mathrm{P}>0.05$; Table II).

Effects of BMI-1 on the biological behavior of A-431 cells Transfection efficiency of BMI-1. siRNA-mediated BMI-1 silencing was used to examine the effect of the BMI-1 protein on the biological behavior of A-431 cells. The highest transfection efficiency was observed at $24 \mathrm{~h}$. Cells were counted under a fluorescence microscope, which revealed that the transfection efficiency was $>80 \%$ at $24 \mathrm{~h}$ (data not shown). Fig. 2 exhibits representative images of fluorescent stained cells.

Protein and messenger RNA (mRNA) levels of BMI-1 are decreased following transfection. The mRNA and protein expression of BMI-1 was assessed by RT-qPCR and western blotting, in order to select the most efficient silencing construct. Tables III and IV and Fig. 3 and 4 reveal that, compared with 
the blank and control siRNA groups, the experimental BMI-1 siRNAs effectively inhibited BMI-1 expression at the mRNA and protein levels in A-431 cells. This was particularly evident in the siRNA-2 group (siRNA-1 group vs. siRNA-2 group, $\mathrm{P}<0.0001$; siRNA-3 group vs. siRNA-2 group, $\mathrm{P}<0.0001$; t-test method). Therefore, siRNA-2 was selected for use in all subsequent experiments.

BMI-1 silencing reduces proliferation and invasion, and enhances apoptosis in A-431 cells. MTT and Annexin V-FITC assays were used to evaluate the proliferation and apoptosis of A-431 cells. The results of the present study revealed that $24 \mathrm{~h}$ following transfection, the cell survival rate of the siRNA-2 group was $53.17 \pm 1.53 \%$, which was significantly reduced compared with that of the blank $(98.77 \pm 0.98 \%)$ and control siRNA groups $(98.79 \pm 1.74 \%$; Table V). The apoptotic rate of the siRNA-2 group was $20.19 \pm 0.04 \%$, which was significantly increased compared with the apoptotic rates of the blank $(5.75 \pm 0.08 \%)$ and control siRNA groups $(5.63 \pm 0.11 \%$; Fig. 5; Table VI). In invasion experiments, the number of penetrating cells in the siRNA-2 group was $21.67 \pm 2.42$, which was significantly reduced compared with the number of penetrating cells in the blank $(33.17 \pm 2.92)$ and control

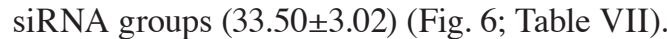

\section{Discussion}

The occurrence and development of VSCC is a multi-step process involving numerous factors. The BMI-1 gene is involved in cell proliferation and apoptosis as an oncogene (5). The results of the present study demonstrate that BMI-1 is overexpressed in VSCC and VIN, which is consistent with the results of previous studies of BMI-1 overexpression in cervical (7), nasopharyngeal (8) and lung cancer (10). A previous study revealed that BMI-1 is expressed in the nucleus, since high BMI-1 expression levels is able to inhibit Ink4a/Arf expression by increasing H2AubiK119 and $\mathrm{H} 3$ metK 27 histone levels via the PCG pathway (15). However, in the present study, BMI-1 was detected mainly in the cytoplasm, suggesting that the target of BMI-1 in VSCC may not be Ink4a/Arf. Further research may be required to elucidate the underlying mechanisms.

The correlation between the BMI-1 expression in tumors, and clinicopathological data, has been investigated in several previous studies. Tong et al (7) demonstrated that overexpression of BMI-1 in cervical cancer was correlated with tumor progression, lymph node metastasis, vascular invasion and HPV infection, suggesting that subtypes of cervical cancer which overexpress BMI-1 may possess a high metastatic potential. Choi et al (16) observed that patients with breast cancer associated with BMI-1 overexpression possessed favorable overall survival rates, particularly amongst patients with estrogen receptor-positive breast cancer. However, in hepatocellular carcinoma, Wang et al (17) reported that overexpression of BMI-1 was not associated with clinicopathological parameters. The results of the aforementioned studies suggest that BMI-1 possesses varying roles in different types of cancer. The results of the present study demonstrated that the overexpression of BMI-1 in VSCC was not correlated with age, pathological stage, lymph node metastasis or degree of differentiation, which was in accordance with the findings of Wang et al (17) and suggests that BMI-1 may be a candidate biomarker for VSCC.
To investigate the effect of BMI-1 on VSCC cell growth and malignant phenotypes, the RNAi method was used in the present study to silence BMI-1 expression in A-431 cells. It was demonstrated that the silencing of BMI-1 may significantly inhibit A-431 cell proliferation through the promotion of apoptosis. Numerous studies have revealed that BMI-1 has a role in tumor development, invasion and metastasis (11-14,18). Destruction of the extracellular matrix and migration into the vascular system are key steps required for tumor metastasis (19). In the present study, it was demonstrated that silencing of BMI-1 expression efficiently decreased the number of invading cells, indicating that BMI-1 may be important in the determination of the invasive ability of VSCC cells.

In conclusion, BMI-1 expression is altered in VIN and VSCC and this may be significant for proliferation, apoptosis and invasion. siRNA targeting of BMI-1 successfully silenced BMI-1 expression in A-431 cells, and silencing BMI-1 significantly promoted apoptosis and inhibited the invasive and metastatic abilities of A-431 cells in vitro. The results of the present study suggest that BMI-1 may be a candidate biomarker for VSCC and may provide an experimental target for VSCC gene therapy.

\section{Acknowledgements}

Funding was received from the first batch of Science and Technology Plan of Liaoning Province (Science and Technology Fund of Liaoning Province; grant no. 2012225016).

\section{References}

1. Canavan TP and Cohen D: Vulvar cancer. Am Fam Physician 66: 1269-1274, 2002.

2. Schottenfeld D and Fraumeni J: Cancer epidemiology and prevention. 3rd ed. 2006.

3. Dittmer C, Katalinic A, Mundhenke C, Thill M, Fischer D. Epidemiology of vulvar and vaginal cancer in Germany. Arch Gynecol Obstet 284: 169-174,2011.

4. Judson PL, Habermann EB, Baxter NN, Durham SB and Virnig BA: Trends in the incidence of invasive and in situ vulvar carcinoma. Obstet Gynecol 107: 1018-1022, 2006.

5. van Lohuizen M1, Verbeek S, Scheijen B, et al: Identification of cooperating oncogenes in E mu-myc transgenic mice by provirus tagging. Cell 65: 737-752, 1991.

6. Silva J, García JM, Peña C, García V, Domínguez G, Suárez D, Camacho FI, Espinosa R, Provencio M, España P and Bonilla F: Implication of polycomb members Bmi-1, Mel-18, and $\mathrm{Hpc}-2$ in the regulation of p16INK4a, p14ARF, h-TERT, and c-Myc expression in primary breast carcinomas. Clin Cancer Res 12: 6929-6936, 2006.

7. Tong YQ, Liu B, Zheng HY, He YJ, Gu J, Li F and Li Y: Overexpression of BMI-1 is associated with poor prognosis in cervical cancer. Asia Pac J Clin Oncol 8: e55-e62, 2012.

8. Yang GF, He WP, Cai MY, He LR, Luo JH, Deng HX, Guan XY, Zeng MS, Zeng YX and Xie D: Intensive expression of Bmi-1 is a new independent predictor of poor outcome in patients with ovarian carcinoma. BMC Cancer 10: 133, 2010.

9. Dong P, Kaneuchi M, Watari H, Hamada J, Sudo S, Ju J and Sakuragi N: MicroRNA-194 inhibits epithelial to mesenchymal transition of endometrial cancer cells by targeting oncogene BMI-1. Mol Cancer 10: 99, 2011.

10. Hu J, Liu YL, Piao SL, Yang DD, Yang YM and Cai L: Expression patterns of USP22 and potential targets BMI-1, PTEN, p-AKT in non-small-cell lung cancer. Lung Cancer 77: 593-599, 2012.

11. Yang Hong, Chao Shang, Yi-Xue Xue, Yun-Hui Liu: Silencing of Bmi-1 Gene Enhances Chemotherapy Sensitivity in Human Glioblastoma Cells. Med Sci Monit 21: 1002-1007, 2015.

12. Jagani Z, Wiederschain D and Loo A: The Polycomb group protein Bmi-1 is essential for the growth of multiple myeloma cells. Cancer Res 70: 5528-5538, 2010. 
13. Wei X, He J, Wang J, Yang X and Ma B: Bmi-1 is essential for the oncogenic potential in CD133+ human laryngeal cancer cells. Tumour Bio Jun 17,2015.

14. Cheng Y, Yang X, Deng X, Zhang X, Li P, Tao J, Lu Q: MicroRNA-218 inhibits bladder cancer cell proliferation, migration, and invasion by targeting BMI-1. Tumour Biol May 14, 2015.

15. Shilatifard A: Chromatin modifications by methylation and ubiquitination: Implications in the regulation of gene expression. Annu Rev Biochem 75: 243-269, 2006.

16. Choi YJ, Choi YL, Cho EY, Shin YK, Sung KW, Hwang YK, Lee SJ, Kong G, Lee JE, Kim JS, et al: Expression of Bmi-1 protein in tumor tissues is associated with favorable prognosis in breast cancer patients. Breast Cancer Res Treat 113: 83-93, 2009.
17. Wang H, Pan K, Zhang HK, Weng DS, Zhou J, Li JJ, Huang W, Song HF, Chen MS and Xia JC: Increased polycomb-group oncogene Bmi-1 expression correlates with poor prognosis in hepatocellular carcinoma. J Cancer Res Clin Oncol 134: 535-541, 2008.

18. Wu J, Hu D, Yang G, Zhou J, Yang C, Gao Y and Zhu Z: Down-regulation of BMI-1 cooperates with artemisinin on growth inhibition of nasopharyngeal carcinoma cells. J Cell Biochem 112: 1938-1948, 2011.

19. Hanahan D and Weinberg RA: Hallmarks of cancer: The next generation. Cell 144: 646-174, 2011. 